\title{
Wearables for gait and balance assessment in the neurological ward - study design and first results of a prospective cross-sectional feasibility study with 384 inpatients
}

Felix P. Bernhard ${ }^{1,2+}$, Jennifer Sartor ${ }^{1,2+}$, Kristina Bettecken ${ }^{1,2+}$, Markus A. Hobert ${ }^{1,2,3}$, Carina Arnold ${ }^{1,2}$, Yvonne G. Weber ${ }^{4}$, Sven Poli ${ }^{5}$, Nils G. Margraf ${ }^{3}$, Christian Schlenstedt ${ }^{3}$, Clint Hansen ${ }^{3 *}$ (D) and Walter Maetzler ${ }^{1,2,3}$

\begin{abstract}
Background: Deficits in gait and balance are common among neurological inpatients. Currently, assessment of these patients is mainly subjective. New assessment options using wearables may provide complementary and more objective information.

Methods: In this prospective cross-sectional feasibility study performed over a four-month period, all patients referred to a normal neurology ward of a university hospital and aged between 40 and 89 years were asked to participate. Gait and balance deficits were assessed with wearables at the ankles and the lower back. Frailty, sarcopenia, Parkinsonism, depression, quality of life, fall history, fear of falling, physical activity, and cognition were evaluated with questionnaires and surveys.

Results: Eighty-two percent $(n=384)$ of all eligible patients participated. Of those, 39\% $(n=151)$ had no gait and balance deficit, 21\% $(n=79)$ had gait deficits, 11\% $(n=44)$ had balance deficits and 29\% $(n=110)$ had gait and balance deficits. Parkinson's disease, stroke, epilepsy, pain syndromes, and multiple sclerosis were the most common diseases. The assessment was well accepted.

Conclusions: Our study suggests that the use of wearables for the assessment of gait and balance features in a clinical setting is feasible. Moreover, preliminary results confirm previous epidemiological data about gait and balance deficits among neurological inpatients. Evaluation of neurological inpatients with novel wearable technology opens new opportunities for the assessment of predictive, progression and treatment response markers.
\end{abstract}

Keywords: Accelerometer, Inertial sensor, Postural control, Neurological diseases

\section{Background}

Gait and balance deficits occur in many neurological diseases. The evaluation of these deficits at the wards of hospitals is often based on qualitative parameters collected by the treating physicians and allied health professionals or on semi-quantitative scoring tools. For example, in Parkinson's disease (PD), the Unified Parkinson Disease Rating Scale

\footnotetext{
* Correspondence: C.Hansen@neurologie.uni-kiel.de

${ }^{\dagger}$ Felix P. Bernhard, Jennifer Sartor and Kristina Bettecken contributed equally to this work.

${ }^{3}$ Department of Neurology, University Hospital Schleswig-Holstein, Campus Kiel, Arnold-Heller-Str. 3, Haus 41, 24105 Kiel, Germany

Full list of author information is available at the end of the article
}

(MDS-UPDRS) is regularly used to rate motor symptoms including gait and postural stability [1]. While such scales, questionnaires and surveys have been subject to multiple validation studies, they have limitations regarding inter-rater variability and subjectivity [2-5].

With the recent and ongoing development of wearables (mainly in the sport and fitness sectors), this technology has reached a sophisticated level making it interesting for medical purposes [6-16]. A particularly relevant field is the complementary assessment of inpatients at neurological wards, as wearables are specifically

(c) The Author(s). 2018 Open Access This article is distributed under the terms of the Creative Commons Attribution 4.0 International License (http://creativecommons.org/licenses/by/4.0/), which permits unrestricted use, distribution, and 
capable of assessing gait and balance deficits which are common in neurological patients $[15,17]$.

Only a small number of studies have investigated feasibility and acceptability of wearables in an inpatient setting, with limitations such as small sample sizes [18] and the investigation of only one disease [19]. This study aims to investigate the feasibility and usefulness of wearables during clinical evaluation in a large sample of neurological inpatients.

\section{Methods}

\section{Participants}

All inpatients referred to the three normal wards of the Neurology Center at the University Hospital of Tübingen between 09/2014 and 04/2015 (16-week assessment periods for each ward) were asked to take part in the study if they were between 40 to 89 years of age (this selection criterion was chosen due to feasibility issues) and were able to walk with or without walking aid. Exclusion criteria were the inability to give informed consent, a fall frequency of more than one fall per week (risk of falls during the assessment too high), and impaired cognition as defined by a Mini Mental State Examination (MMSE) score below 10 points. Participants who had at least one fall during the last 2 years were defined as fallers. The ethics committee of the medical faculty of the University of Tübingen approved the study (No. 356/2014BO2) and all participants gave written informed consent prior to participation.

\section{Quantitative gait and balance assessment}

Participants were equipped with a wearable sensor system (Rehawatch ${ }^{\circ}$, Hasomed, Magdeburg, Germany) consisting of three sensor-units worn at both ankles and at the lower back (L4-L5) [20]. Each sensor-unit contains 3D accelerometers $( \pm 8 \mathrm{~g}), 3 \mathrm{D}$ gyroscopes $( \pm 2000 \% \mathrm{~s})$ and $3 \mathrm{D}$ magnetometers $( \pm 1.3 \mathrm{Gs})$ resulting in nine degrees of freedom and the raw data was processed and analyzed using validated and company provided algorithms [21]. The assessment included the following tasks: Participants walked seven times a $20 \mathrm{~m}$ distance under single (slow, comfortable, and fast speed) and dual tasking conditions (checking boxes and subtracting serial $7 \mathrm{~s}$ during comfortable and fast walking) $[22,23]$. Static balance during quiet standing at the center of stability was tested on flat ground with four different positions of the feet for 30 s each: open stance with feet placed in parallel position with $5-10 \mathrm{~cm}$ in between, closed stance (parallel position), semi-tandem stance, and tandem stance [24]. The task one difficulty level below the one successfully performed on flat ground was then performed for $30 \mathrm{~s}$ on a foam pad (Airex balance pad, $50 \times 41 \times 6 \mathrm{~cm})$. Static balance at the limit of stability was tested with an adapted version of the Functional Reach Test [25] over a 15 s period. Overall mobility and transfer was tested with the Timed-Up-and-Go test (TUG) under comfortable and fast speed conditions [26-28]. Muscle strength was assessed with a hydraulic hand dynamometer (DanMic Global $^{\circ}$, San Jose, USA) and muscle mass with bioimpedance (Akern Bia 101, SMT medical GmbH\&Co. KG, Würzburg, Germany).

\section{Assessments with scales and questionnaires}

Fear of falling was assessed with the German version of the Falls Efficacy Scale-International (FES-I) [29]. Self-concepts of health, activity, cognition, social support and risk factors for age-associated diseases were assessed [30]. Depression was evaluated with the German version of the Beck's Depression Inventory II (BDI-II) [31, 32]. Health-related quality of life was assessed with the EQ-5D-5 L. This scale addresses mobility, autonomy, pain, fear, despondence, daily living activities and health [33]. The MMSE [34] and the Trail Making Test (TMT) [35] were used to assess cognition, and part III of the Movement Disorders Society-sponsored Unified Parkinson's Rating Scale (MDS-UPDRS) [1] was used for the assessment of motor symptoms. Function of the sensory nerves was assessed at the medial malleoli of the lower extremities and the basal joint of each thumb with a Rydel Seiffer tuning fork.

\section{Classification of impaired gait and balance}

A gait deficit was defined as $>15 \%$ lower walking speed compared to mean age-corrected speed according to $[36,37]$. Presence of a balance deficit was considered when tandem stance could be performed no longer than $10 \mathrm{~s}[38,39]$.

\section{Statistical analysis}

Statistical analysis was conducted with JMP 11.1.1 (SAS). Demographic data of the different groups were compared with Kruskal-Wallis-test (or Fisher's exact test for categorical data). Post hoc testing was performed with Mann-Whitney-U test. $P$ values below 0.05 were considered significant. Bonferroni correction for multiple testing was applied for post-hoc tests $(p<0.0083)$.

\section{Results}

Of 468 inpatients eligible for the study (i.e., fulfilled all inclusion criteria and no exclusion criterion, and were not excluded due to logistic reasons), 384 (82\%) participated. Of those, $60 \%$ were male. Mean age of the cohort was 62 years. The 10 most common diagnoses $(69 \%$ of all investigated patients) were Parkinson's disease (PD, $n$ $=51)$, stroke $(n=50)$, epilepsy $(n=30)$, pain syndromes $(n=26)$, multiple sclerosis (MS, $n=23)$, CNS tumours 


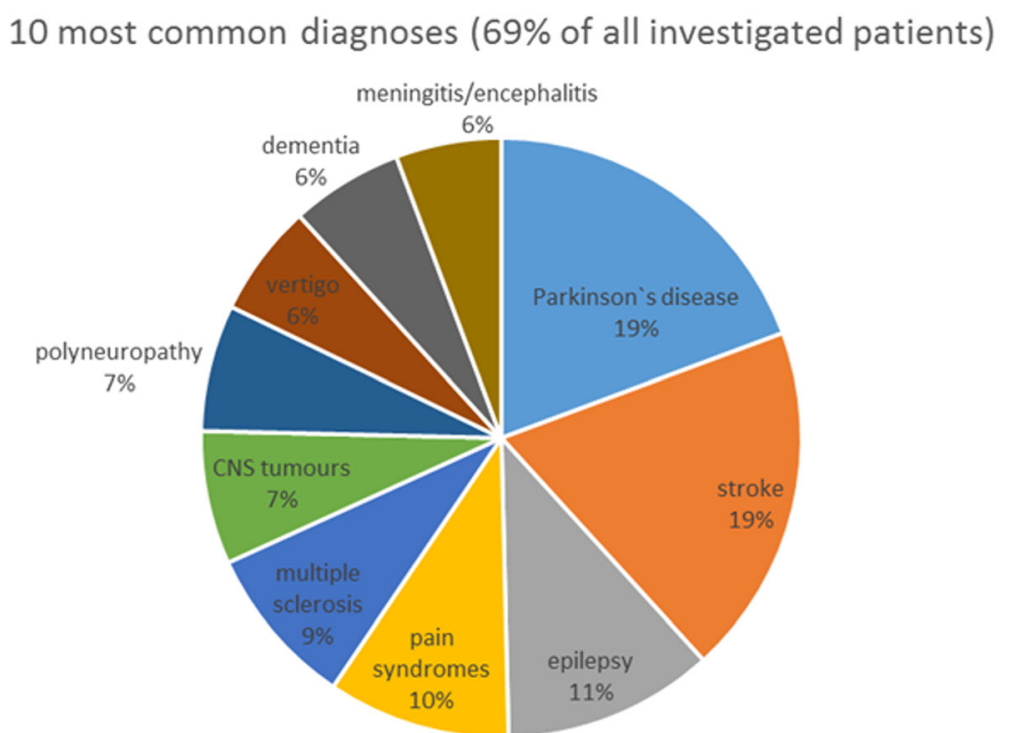

Fig. 1 Graphical representation of the ten most common diagnoses within the 384 study participants

( $n=19)$, polyneuropathy $(n=18)$, vertigo $(n=16)$, dementia $(\mathrm{n}=16)$, and meningitis/encephalitis $(n=15)$. During the study, no severe adverse events occurred (Fig. 1).

One hundred and 51 participants (39\%) had no gait and balance deficit (control group), 79 (21\%) had a gait deficit, 44 (11\%) had a balance deficit and 110 (29\%) had a gait and balance deficit. The highest proportion of patients with gait deficits (33\%) was found in the meningitis/encephalitis cohort, the highest proportion of patients with balance deficits (17\%) in the MS cohort, and the highest proportion of participants with gait and balance deficits $(41 \%)$ in the PD cohort. Patients with pain syndromes had rarely gait and/or balance deficits.

Patients complied well with the quantitative gait and balance assessment and descriptive results from the balance, gait and postural transitions are shown in Figs. 2, 3 and 4.

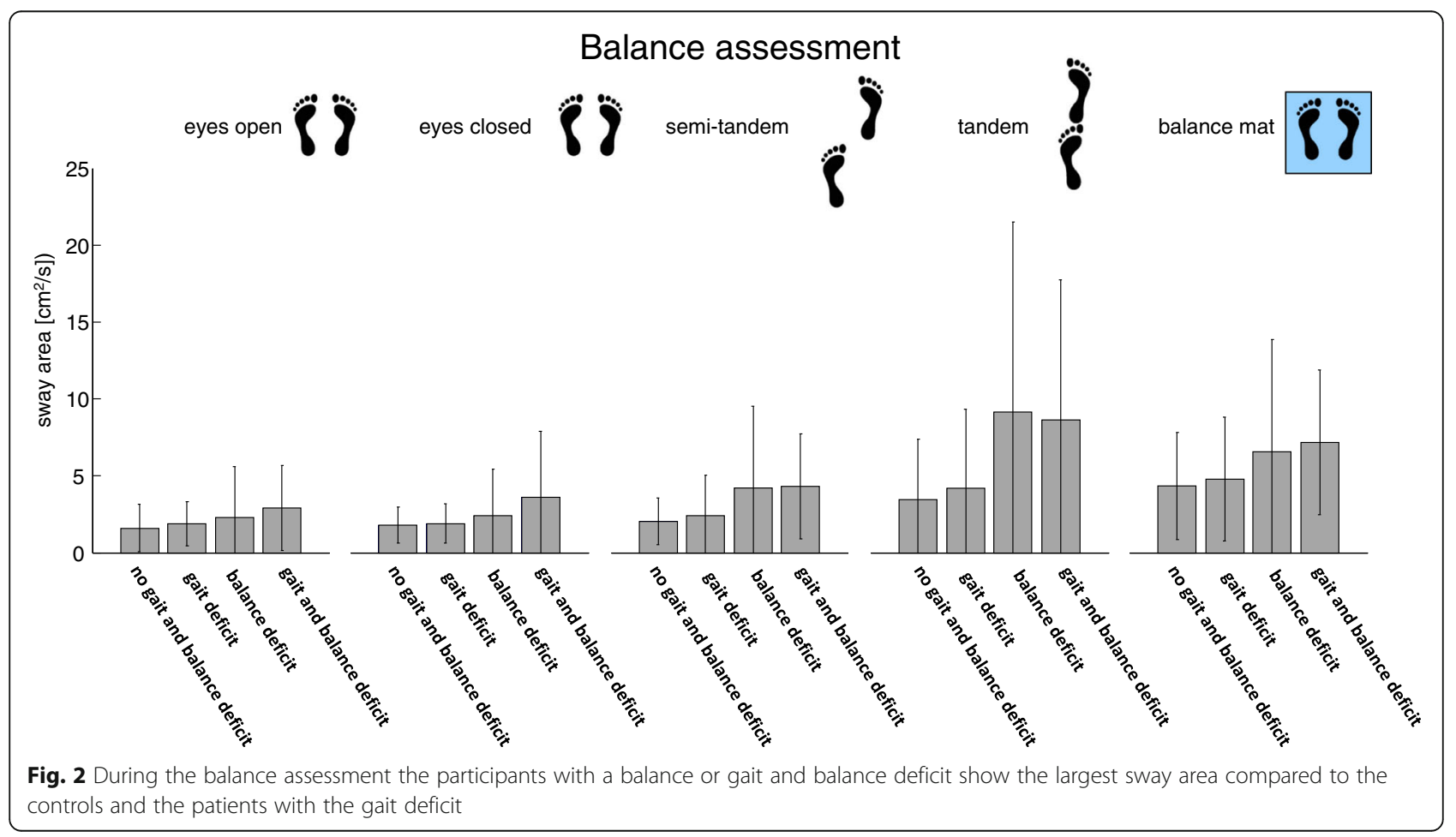




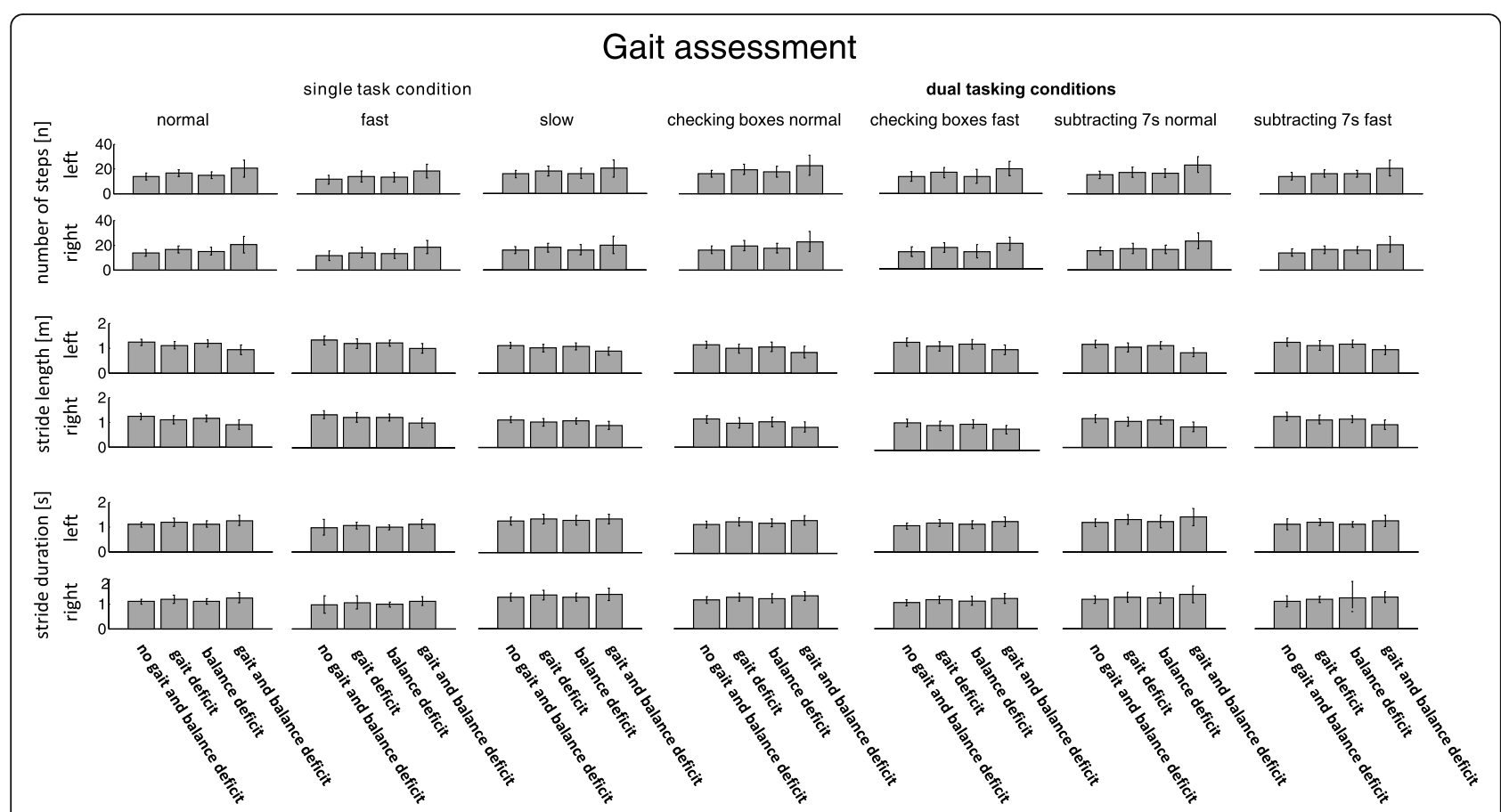

Fig. 3 During the gait assessments (single and dual task conditions) the participants with a gait or gait and balance deficit show the largest number of steps, the smallest stride length and the highest stride duration compared to the controls and the participants with a balance deficit

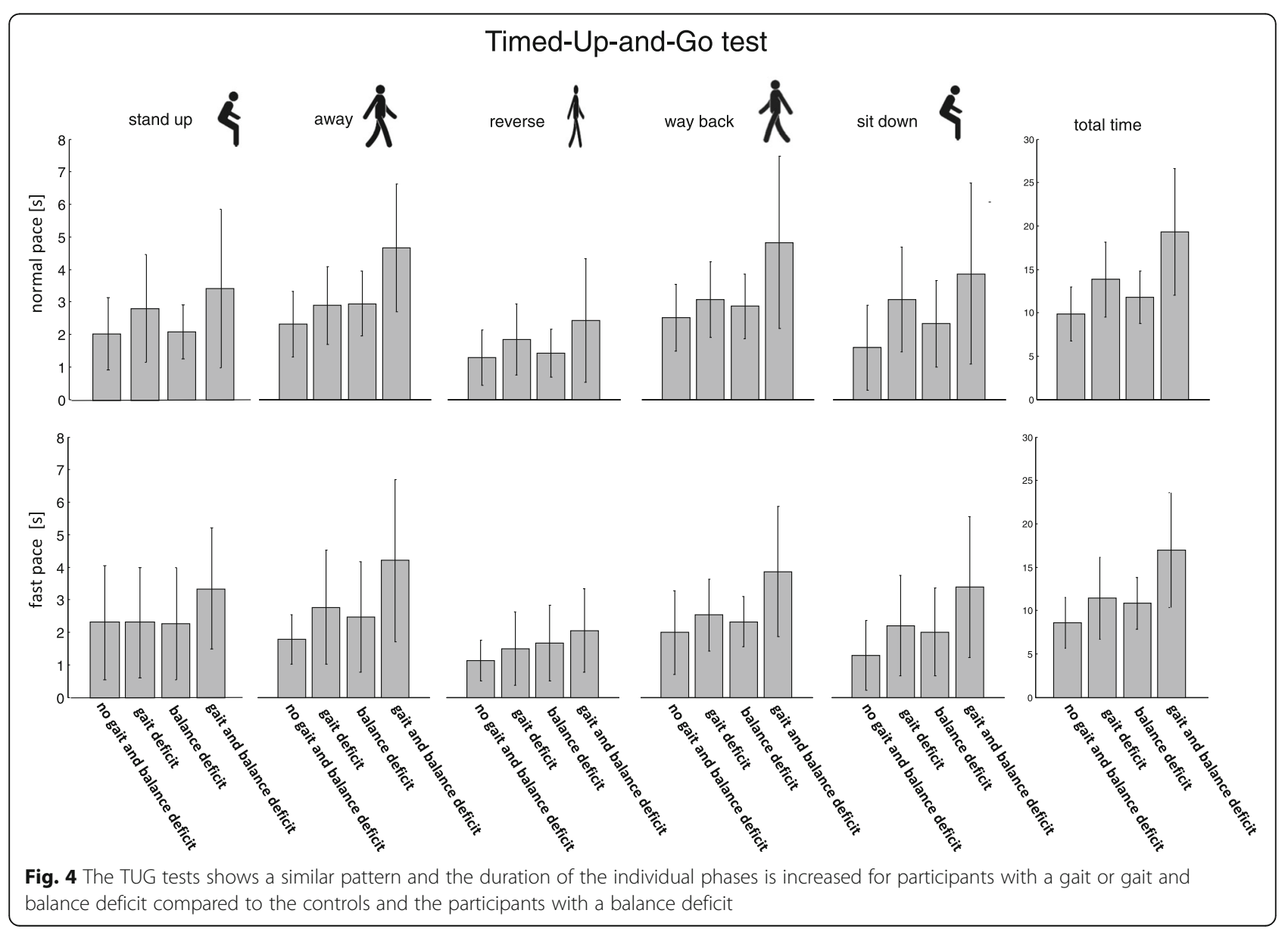


MMSE and TMT performances were significantly worse in all cohorts with gait and/or balance deficits, compared to the control cohort. Moreover, the cohort with gait and balance deficits performed worse in the TMT compared to the group with gait deficits. TUG durations were slower in the cohort with gait and balance deficits than in both the gait deficit cohort and the balance deficit cohort, and fastest in the control cohort. The same pattern was observed with regard to fear of falling, with highest FES-I values (i.e. the highest fear of falling) in the gait and balance deficits cohort. BDI II values were higher in the cohort with gait and balance deficits, compared to the control cohort. The cohort with gait and balance deficits had lower grip force when compared to the cohort with gait deficits and the control cohort. A more detailed description of the inter-cohort comparisons is presented in Table 1.

\section{Discussion}

In the presented study, we performed routine clinical gait and balance assessments complemented by an exhaustive evaluation of geriatric parameters in a neurological department at a university hospital. To the best of our knowledge, this is the first sensor-based cross-sectional study in a clinical environment of a university hospital, covering a wide range of neurological diseases. Our overall cohort represents a wide range and representative number of neurological diseases. A study with a similar setting but without sensor-unit-based assessments displayed a comparable composition of neurological diseases [17] with the five most common diagnoses completely overlapping.

Acceptance of sensor-unit-based assessments in our study was high. Only $18 \%$ of eligible patients refused to take part in the study. We did not experience any logistical issues during the assessments. The sensor system

Table 1 Demographic, clinical, and semiquantitative/quantitative study outcomes of the whole cohort, as well as of the subcohorts with and without gait and balance deficits

\begin{tabular}{|c|c|c|c|c|c|c|c|c|c|c|c|}
\hline & \multicolumn{2}{|c|}{$\begin{array}{l}\text { Whole cohort } \\
(N=384)\end{array}$} & \multicolumn{2}{|l|}{$\begin{array}{l}\text { Controls } \\
(N=151)\end{array}$} & \multicolumn{2}{|c|}{$\begin{array}{l}\text { Gait deficits } \\
(N=79)\end{array}$} & \multicolumn{2}{|c|}{$\begin{array}{l}\text { Balance deficits } \\
(N=44)\end{array}$} & \multicolumn{2}{|c|}{$\begin{array}{l}\text { Gait and balance deficits } \\
(N=110)\end{array}$} & \multirow[t]{2}{*}{$P$-Value } \\
\hline & Median & Range & Median & Range & Median & Range & Median & Range & Median & Range & \\
\hline Age [years] & 64 & $40-90$ & 57 & $40-86$ & 60 & $40-89$ & $70^{* \#}$ & $44-89$ & $69.5^{* \#}$ & $41-90$ & $<0.0001$ \\
\hline Gender [\% female] & 42.4 & & 43.0 & & 36.7 & & 43.2 & & 45.5 & & 0.67 \\
\hline Height [m] & 1.72 & $1.48-2.01$ & 1.73 & $1.49-2.01$ & 1.73 & $1.48-1.98$ & 1.70 & $1.58-1.88$ & 1.70 & $1.49-2.00$ & 0.04 \\
\hline Weight [kg] & 79 & $37-134$ & 80 & $50-134$ & 82 & $46-117$ & 79 & $55-115$ & 74 & $37-123$ & 0.13 \\
\hline BMI $\left[\mathrm{kg} / \mathrm{m}^{2}\right]$ & 26.2 & $14.9-43.0$ & 26.3 & $19.4-41.8$ & 26.4 & $17.3-41.6$ & 26.8 & $19.4-38.4$ & 25.9 & $14.9-43.0$ & 0.77 \\
\hline $\begin{array}{l}\text { Falls in the last } 24 \\
\text { months [N] }\end{array}$ & 0 & $0-100$ & 0 & $0-50$ & 0 & $0-50$ & $1^{*}$ & $0-55$ & $1^{* \#}$ & $0-100$ & $<0.0001$ \\
\hline $\begin{array}{l}\text { At least one fall in the last } \\
24 \text { months [\%] }\end{array}$ & 46 & & 29 & & 42 & & $62^{*}$ & & $65^{* \#}$ & & $<0.0001$ \\
\hline LACHS (0-15) & 3 & $0-10$ & 2 & $0-8$ & $3^{*}$ & $0-6$ & $3^{*}$ & $1-9$ & $4^{* \#}$ & $0-10$ & $<0.0001$ \\
\hline MMSE (0-30) & 28 & $13-30$ & 29 & $24-30$ & $28^{*}$ & $13-30$ & $28^{*}$ & $13-30$ & $27^{*}$ & $13-30$ & $<0.0001$ \\
\hline TMT-A [s] & 49 & $13-300$ & 38 & $13-300$ & $48^{*}$ & $23-300$ & $55^{*}$ & $26-300$ & $72^{* \#}$ & $17.7-300$ & $<0.0001$ \\
\hline TMT-B [s] & 149 & $34-300$ & 101 & $34-300$ & $129^{*}$ & $38-300$ & $174^{*}$ & $60-300$ & $300^{* \#}$ & $38.8-300$ & $<0.0001$ \\
\hline$\Delta \mathrm{TMT}[\mathrm{s}]$ & 85 & $-30-280$ & 60 & $-30-280$ & $78^{*}$ & $0-253$ & 98 & $0-257$ & $149^{*}$ & $0-270$ & $<0.0001$ \\
\hline $\begin{array}{l}\text { Timed up and go } \\
\text { convenient speed [s] }\end{array}$ & 12 & $6-92$ & 10 & $6-25$ & $12^{*}$ & $8-28$ & $11^{*}$ & $8-18$ & $16^{* \#+}$ & $8-92$ & $<0.0001$ \\
\hline $\begin{array}{l}\text { Timed up and go fast } \\
\text { speed [s] }\end{array}$ & 9 & $5-47$ & 7 & $5-15$ & $10^{*}$ & $6-22$ & $11^{*}$ & $6-15$ & $14^{* \#+}$ & $7-47$ & $<0.0001$ \\
\hline BDI II (0-63) & 10 & $0-51$ & 8 & $0-51$ & 10 & $0-28$ & 10 & $0-38$ & $12^{*}$ & $0-51$ & 0.0004 \\
\hline FES-I (0-64) & 20 & $0-64$ & 18 & $0-63$ & $21^{*}$ & $0-44$ & $20^{*}$ & $14-48$ & $27^{* \#+}$ & $14-64$ & $<0.0001$ \\
\hline EQ5D VAS (0-100) & 60 & $1-100$ & 70 & $20-100$ & 55 & 10-95 & $50^{*}$ & $5-90$ & $50^{* \#}$ & $1-95$ & $<0.0001$ \\
\hline Functional Reach $[\mathrm{cm}]$ & 23 & $3-82$ & 27 & $8-45$ & $23^{*}$ & $3-82$ & $20^{*}$ & $5-35$ & $18^{* \#}$ & $5-34$ & $<0.0001$ \\
\hline Gait speed $[\mathrm{m} / \mathrm{s}]$ & 1.10 & $0.27-2.33$ & 1.34 & $0.95-2.33$ & $0.99^{*}$ & $0.56-1.67$ & $1.15^{* \#}$ & $0.81-2.03$ & $0.80^{* \#+}$ & $0.27-1.5$ & $<0.0001$ \\
\hline Grip force [kg] & 27 & $3-76$ & 29 & $10-76$ & 29 & $7-56$ & 28 & $15-51$ & $23^{* \#}$ & $3-51$ & $<0.0001$ \\
\hline
\end{tabular}

Data is presented with median and range. P-values were calculated using the Kruskal-Wallis-test, with post hoc Mann-Whitney-U-Test and Chi ${ }^{2}$ test. For post hoc testing Bonferroni correction for multiple testing was applied. ${ }^{*} p<0.0083$ for comparison with the control cohort group, ${ }^{\#} p<0.0083$ for comparison with the gait deficit cohort, ${ }^{+} p<0.0083$ for comparison with the balance deficit cohort. BDI II Beck's depression inventory II, BMI Body mass index, EQ5D VAS Visual analog scale of the EuroQol-5 dimension questionnaire, FES-I Falls efficacy scale international, LACHS Geriatric screening according to Lachs et al., MMSE Mini-mental state examination, TMT Trail making test (part $\mathrm{A}, \mathrm{B}$, and $\mathrm{B}-\mathrm{A}=\Delta \mathrm{TMT}$ ) 
was easy and quick to apply and none of the patients felt restricted by the sensor system. Moreover, no serious adverse events, e.g. falls, occurred. These results bode well for the clinical uptake of wearable sensors into regular care.

Not surprisingly, frequencies of gait and balance deficits of neurological inpatients are higher compared to observations in the community and in outpatient clinics. However, these deficits are ubiquitously observed. In a community-based study investigating 467 participants, the prevalence of gait deficits was $14 \%$ in those between 67 and 74 years of age, $29 \%$ in those between 75 and 84 years and $49 \%$ in those 85 years and older [40]. In a cross-sectional investigation of 488 community residing adults aged between 60 and 97 years, 32\% of the cohort presented with impaired gait and the prevalence increased with age. However, $38 \%$ of the subjects aged 80 years and older still had a normally preserved gait [41]. In outpatients clinics, gait deficits occur in $35 \%$ of patients, most of them having neurological causes [42].

It is of note that, in our study, the cohort with gait (but not balance) deficits was of similar age as the control cohort. This suggests that the slower gait speed of this group was not induced by an overall decline in performance due to aging, but rather due to the underlying disease processes. This could be an interesting observation in the light of ongoing studies investigating gait speed as a relevant outcome parameter for disease and disability. Moreover, groups with gait and/or balance deficits showed impaired cognitive performance compared to the control group, supporting the association between motor performance and cognition [43-45]. It is also of note that not only the balance deficit cohort but also the gait deficit cohort performed worse than the controls in the functional reach test. This finding supports the link between static balance and gait and reflects the various aspects of postural control which should be further investigated in future studies.

The current study has several limitations. First, only gait velocity was used to define gait deficits. Although reduced gait speed impacts patients' mobility, there are several additional gait variables (e.g. gait variability, asymmetry) which are important features as they are associated with fall risk [46-49]. However, numerous more sophisticated algorithms are currently developed and validated allowing investigation of the multidimensional aspects of postural control (e.g., $[20,50,51])$ in more detail. Including dynamic, proactive, and reactive postural control parameters will give a broader view of the multidimensional aspects of balance control and help understand different pathologies of the diseases. This aspect is currently the focus of a more detailed sensor-unit-based analysis of the dataset.

\section{Conclusion}

In conclusion, this study shows that the use of inertial sensors in a clinical setting by investigating patients in neurological wards of a university hospital over a time of 16 weeks is feasible. These results should motivate to further design inpatient assessments using wearable technology, and of collaborative projects using such datasets for further in-depth analyses.

\section{Abbreviations \\ BDI-II: Beck's Depression Inventory II; EQ-5D-5 L: Instrument to assess health- related quality of life; FES-I: Falls Efficacy Scale-International; MDS- \\ UPDRS: Movement Disorders Society-sponsored Unified Parkinson's Rating Scale; MMSE: Minimal Mental State Examination; PD: Parkinson's disease; \\ TMT: Trail Making Test; TUG: Timed-Up-and-Go test}

\section{Acknowledgements}

We thank all participants who took part in the study and the financial support by Land Schleswig-Holstein within the funding programme Open Access Publikationsfonds.

\section{Funding}

We acknowledge financial support by Land Schleswig-Holstein within the funding programme Open Access Publikationsfonds.

\section{Availability of data and materials \\ Due to ethical restrictions imposed by the Ethics Committee of the Medical Faculty of the University of Tuebingen related to approved patient consent procedure and protecting patient privacy, all relevant data should be requested at Prof. Maetzler directly using the email address w.maetzler@neurologie.uni-kiel.de. The Ethical Committee decided how data of this particular study should be handled by the researchers, however, the Ethical Committee does not have access to the actual datas.}

\section{Authors' contributions}

WM, FPB, and $\mathrm{KB}$, conceived and planned the experiments. FPB, JS, KB, MAH, $C A, Y G W$, and SP carried out the experiments. $F P B, N M G, C S, C H$, and WM contributed to the interpretation of the results and took the lead in writing the manuscript. All authors provided critical feedback and helped shape the research, analysis and manuscript. All authors read and approved the final manuscript.

\section{Ethics approval and consent to participate}

The ethics committee of the medical faculty of the University of Tübingen approved the study and all participants gave written informed consent prior to participation.

\section{Consent for publication}

This submission is made in agreement with my colleagues who were fully involved in the study and preparation of the manuscript. Each of the authors has read and concurs with the content in the final manuscript.

\section{Competing interests}

The authors declare that they have no competing interests.

\section{Publisher's Note}

Springer Nature remains neutral with regard to jurisdictional claims in published maps and institutional affiliations.

\section{Author details}

${ }^{1}$ Department of Neurology and Neurodegenerative Diseases and Hertie Institute for Clinical Brain Research, University Tübingen, 72076 Tübingen, Germany. ${ }^{2}$ DZNE, German Center for Neurodegenerative Diseases, Tuebingen, Germany. ${ }^{3}$ Department of Neurology, University Hospital Schleswig-Holstein, Campus Kiel, Arnold-Heller-Str. 3, Haus 41, 24105 Kiel, Germany. ${ }^{4}$ Department of Neurology and Epileptology, University Tübingen, 72076 Tübingen, Germany. ${ }^{5}$ Department of Neurology \& Stroke, University Hospital Tübingen, Tübingen, Germany. 


\section{Received: 23 April 2018 Accepted: 26 July 2018}

\section{Published online: 16 August 2018}

\section{References}

1. Goetz CG, Tilley BC, Shaftman SR, Stebbins GT, Fahn S, Martinez-Martin P, et al. Movement Disorder Society-sponsored revision of the unified Parkinson's disease rating scale (MDS-UPDRS): scale presentation and clinimetric testing results. Mov Disord. 2008;23:2129-70.

2. Parry SW, Deary V, Finch T, Bamford C, Sabin N, McMeekin P, et al. The STRIDE (strategies to increase confidence, InDependence and energy) study: cognitive behavioural therapy-based intervention to reduce fear of falling in older fallers living in the community - study protocol for a randomised controlled trial. Trials. 2014;15:210.

3. Canning C, Sherrington C, Lord S, Fung V, Close J, Latt M, et al. Exercise therapy for prevention of falls in people with Parkinson's disease: a protocol for a randomised controlled trial and economic evaluation. BMC Neurol. 2009:9:4.

4. Wong TH, Nguyen HV, Chiu MT, Chow KY, Ong MEH, Lim GH, et al. The low fall as a surrogate marker of frailty predicts long-term mortality in older trauma patients. PLoS One. 2015;10:1-14.

5. Veuas BJ, Wayne SJ, Romero LJ, Baumgartner RN, Garry P. Fear of falling and restriction of mobility in elderly fallers. Age Ageing. 1997;26:189-93.

6. Starkstein SE, Merello M. The unified parkinson's disease rating scale: validation study of the mentation, behavior, and mood section. Mov Disord. 2007;22:2156-61. Available from: http:/www.ncbin.nlm.nih.gov/pubmed/ 17721877

7. Rampp A, Barth J, Schuelein S, Gassmann K-G, Klucken J, Eskofier BM. Inertial sensor-based stride parameter calculation from gait sequences in geriatric patients. IEEE Trans Biomed Eng. 2015;62:1089-97. Available from: http:// ieeexplore.ieee.org/document/6949634/.

8. Schülein S, Barth J, Rampp A, Rupprecht R, Eskofier BM, Winkler J, et al. Instrumented gait analysis: a measure of gait improvement by a wheeled walker in hospitalized geriatric patients. J Neuroeng Rehabil. 2017;14:18. Available from: http://jneuroengrehab.biomedcentral.com/articles/10.1186/ s12984-017-0228-z.

9. Klucken J, Barth J, Kugler P, Schlachetzki J, Henze T, Marxreiter F, et al. Unbiased and mobile gait analysis detects motor impairment in Parkinson's disease. PLoS One. 2013;8:e56956. Available from: http://dx.plos.org/10. 1371/journal.pone.0056956

10. Bianchi MT. Sleep devices: wearables and nearables, informational and interventional, consumer and clinical. Metabolism. 2018;84:99-108. https:// doi.org/10.1016/j.metabol.2017.10.008.

11. Torous J, Firth J, Mueller N, Onnela JP, Baker JT. Methodology and reporting of mobile heath and smartphone application studies for schizophrenia. Harv Rev Psychiatry. 2017;25:146-54.

12. Pevnick JM, Birkeland K, Zimmer R, Elad Y, Kedan I. Wearable technology for cardiology: an update and framework for the future. Trends Cardiovasc Med. 2018;28:144-50.

13. Haghi M, Thurow K, Stoll R. Wearable devices in medical internet of things: scientific research and commercially available devices. Healthc Inform Res. 2017;23:4-15.

14. Cahn A, Akirov A, Raz I. Digital health technology and diabetes management. J Diabetes. 2018;10:10-7.

15. Vienne A, Barrois RP, Buffat S, Ricard D, Vidal P-P. Inertial sensors to assess gait quality in patients with neurological disorders: a systematic review of technical and analytical challenges. Front Psychol. 2017;8:817.

16. Maetzler W, Klucken J, Horne M. A clinical view on the development of technology-based tools in managing Parkinson's disease. Mov Disord. 2016; 31:1263-71.

17. Stolze H, Klebe S, Baecker C, Zechlin C, Friege L, Pohle S, et al. Prevalence of gait disorders in hospitalized neurological patients. Mov Disord. 2005;20:89-94

18. Arora S, Venkataraman V, Zhan A, Donohue S, Biglan KM, Dorsey ER, et al. Detecting and monitoring the symptoms of Parkinson's disease using smartphones: a pilot study. Parkinsonism Relat Disord. 2015;21:650-3. Available from: https:/www.sciencedirect.com/science/article/pii/ S1353802015000814

19. Silva de Lima AL, Hahn T, Evers LJW, de Vries NM, Cohen E, Afek M, et al. Feasibility of large-scale deployment of multiple wearable sensors in Parkinson's disease. PLoS One. 2017:12:e0189161. Available from: http://dx. plos.org/10.1371/journal.pone.0189161 .
20. Pham MH, Elshehabi M, Haertner L, Din SD, Srulijes K, Heger T, et al. Validation of a step detection algorithm during straight walking and turning in patients with Parkinson's disease and older adults using an inertial measurement unit at the lower back. Front Neurol. 2017:8:457.

21. Donath L, Faude O, Lichtenstein E, Nüesch C, Mündermann A. Validity and reliability of a portable gait analysis system for measuring spatiotemporal gait characteristics: comparison to an instrumented treadmill. J Neuroeng Rehabil. 2016;13:6. Available from: http://www.ncbi.nlm.nih.gov/pubmed/ 26790409 .

22. Hobert MA, Niebler R, Meyer SI, Brockmann K, Becker C, Huber H, et al. Poor Trail making test performance is directly associated with altered dual task prioritization in the elderly - baseline results from the TREND study. PLoS One. $2011 ; 6: \mathrm{e} 27831$.

23. Elshehabi M, Maier KS, Hasmann SE, Nussbaum S, Herbst H, Heger T, et al. Limited effect of dopaminergic medication on straight walking and turning in early to moderate Parkinson's disease during single and dual tasking. Front Aging Neurosci. 2016;8:4.

24. Maetzler W, Mancini M, Liepelt-Scarfone I, Müller K, Becker C, van Lummel RCRC, et al. Impaired trunk stability in individuals at high risk for Parkinson's disease. PLoS One. 2012;7:e32240. 2012/03/30

25. Hasmann SE, Berg D, Hobert MA, Weiss D, Lindemann U, Streffer J, et al. Instrumented functional reach test differentiates individuals at high risk for Parkinson's disease from controls. Front Aging Neurosci. 2014;6: 286.

26. Podsiadlo D, Richardson S. The timed "up \& go": a test of basic functional mobility for frail elderly persons. 1991.

27. Van Uem JMT, Walgaard S, Ainsworth E, Hasmann SE, Heger T, Nussbaum S, et al. Quantitative timed-up-and-go parameters in relation to cognitive parameters and health-related quality of life in mild-to-moderate Parkinson's disease. PLoS One. 2016;11:e0151997. Available from: http://dx.plos.org/10. 1371/journal.pone.0151997

28. Weiss A, Herman T, Plotnik M, Brozgol M, Maidan I, Giladi N, et al. Can an accelerometer enhance the utility of the timed up \& go test when evaluating patients with Parkinson's disease? Med Eng Phys. 2010;32:119-25.

29. Dias N, Kempen GIJM, Beyer N, Freiberger E, Yardley L. Die Deutsche Version der Falls Efficacy Scale-International Version. Z Gerontol Geriatr. 2006;39:297. https://doi.org/10.1007/s00391-006-0400-8.

30. Lachs MS, Becker M, Siegal AP, Miller RL, Tinetti ME. Delusions and behavioral disturbances in cognitively impaired elderly persons. J Am Geriatr Soc. 1992:40:768-73.

31. Kühner C, Bürger C, Keller F, Hautzinger M. Reliabilität und Validität des revidierten Beck-Depressionsinventars (BDI-II). Nervenarzt. 2007;78:651-6.

32. Beck AT, Beamesderfer A. Assessment of depression: the depression inventory. Mod Probl Pharmacopsychiatry. 1974;7:151-69. Cited 22 Mar 2018. Available from: http://www.ncbi.nlm.nih.gov/pubmed/4412100.

33. EuroQol Group. EuroQol--a new facility for the measurement of healthrelated quality of life. Health Policy. 1990;16:199-208. Available from: http:// www.ncbi.nlm.nih.gov/pubmed/10109801 .

34. Folstein MF, Folstein SE, McHugh PR. Mini-mental state: a practical method for grading the state of patients for the clinician. J Psychiatr Res. 1975;12: 189-98.

35. Brown EC, Casey A, Fisch Rl, Neuringer C. Trial making test as a screening device for the detection of brain damage. J Consult Psychol. 1958:22:46974. Available from: http://www.ncbi.nlm.nih.gov/pubmed/13611107 .

36. Bohannon RW, Williams AA. Normal walking speed: a descriptive metaanalysis. Physiotherapy. 2011;97:182-9.

37. Studenski S, Perera S, Patel K, Rosano C, Faulkner K, Inzitari M, et al. Gait speed and survival in older adults. JAMA. 2011;305:50-8.

38. Amadori K, Püllen R, Steiner T. Gangstörungen im Alter. Nervenarzt. 2014;85: $761-72$

39. Guralnik JM, Ferrucci L, Simonsick EM, Salive ME, Wallace RB. Lowerextremity function in persons over the age of 70 years as a predictor of subsequent disability. N Engl J Med. 1995;332:556-61.

40. Odenheimer G, Funkenstein HH, Beckett L, Chown M, Pilgrim D, Evans D, et al. Comparison of neurologic changes in "successfully aging" persons vs the Total aging population. Arch Neurol. 1994;51:573-80. American Medical Association

41. Mahlknecht P, Kiechl S, Bloem BR, Willeit J, Scherfler C, Gasperi A, et al. Prevalence and burden of gait disorders in elderly men and women aged 60-97 years: a population-based study. PLoS One. 2013;8:e69627. Available from: http://dx.plos.org/10.1371/journal.pone.0069627. 
42. Verghese J, LeValley A, Hall CB, Katz MJ, Ambrose AF, Lipton RB. Epidemiology of gait disorders in community-residing older adults. J Am Geriatr Soc. 2006;54:255-61.

43. Fitzpatrick AL, Buchanan CK, Nahin RL, Dekosky ST, Atkinson HH, Carlson $M C$, et al. Associations of gait speed and other measures of physical function with cognition in a healthy cohort of elderly persons. J Gerontol A Biol Sci Med Sci. 2007;62:1244-51. Available from: http://www.ncbi.nlm.nih. gov/pubmed/18000144

44. Parihar R, Mahoney JR, Verghese J. Relationship of gait and cognition in the elderly. Curr Transl Geriatr Exp Gerontol Rep. 2013;2:167-73. Available from: http://link.springer.com/10.1007/s13670-013-0052-7.

45. Verghese J, Lipton RB, Katz MJ, Hall CB, Derby CA, Kuslansky G, et al. Leisure activities and the risk of dementia in the elderly. N Engl J Med. 2003;348: 2508-16. Available from: http://www.nejm.org/doi/abs/10.1056/ NEJMoa022252.

46. Hausdorff JM, Rios DA, Edelberg HK. Gait variability and fall risk in community-living older adults: a 1-year prospective study. Arch Phys Med Rehabil. 2001;82:1050-6. Available from: http://linkinghub.elsevier.com/ retrieve/pii/S0003999301632155

47. Johansson J, Nordström A, Nordström P. Greater fall risk in elderly women than in men is associated with increased gait variability during multitasking. J Am Med Dir Assoc. 2016;17:535-40. Available from: http://www.ncbi.nlm. nih.gov/pubmed/27006336.

48. Dadashi F, Mariani B, Rochat S, Büla CJ, Santos-Eggimann B, Aminian K. Gait and foot clearance parameters obtained using shoe-worn inertial sensors in a large-population sample of older adults. Sensors (Basel). 2013;14:443-57. Available from: http://www.mdpi.com/1424-8220/14/1/443 .

49. Del Din S, Godfrey A, Rochester L. Validation of an accelerometer to quantify a comprehensive battery of gait characteristics in healthy older adults and Parkinson's disease: toward clinical and at home use. IEEE J Biomed Heal Informatics. 2016;20:838-47.

50. Mancini M, Chiari L, Holmstrom L, Salarian A, Horak FB. Validity and reliability of an IMU-based method to detect APAs prior to gait initiation. Gait Posture. 2016;43:125-31. Available from: http://www.ncbi.nlm.nih.gov/ pubmed/26433913.

51. Pham MH, Elshehabi M, Haertner L, Heger T, Hobert MA, Faber GS, et al. Algorithm for turning detection and analysis validated under home-like conditions in patients with Parkinson's disease and older adults using a 6 degree-of-freedom inertial measurement unit at the lower back. Front Neurol. 2017;8:135. Available from: http://journal.frontiersin.org/article/10. 3389/fneur.2017.00135/full.

Ready to submit your research? Choose BMC and benefit from:

- fast, convenient online submission

- thorough peer review by experienced researchers in your field

- rapid publication on acceptance

- support for research data, including large and complex data types

- gold Open Access which fosters wider collaboration and increased citations

- maximum visibility for your research: over $100 \mathrm{M}$ website views per year

At BMC, research is always in progress.

Learn more biomedcentral.com/submissions 